\title{
Negotiating the "Relevant" in Culturally Relevant Mathematics
}

\author{
Noel Enyedy, University of California Los Angeles \\ Joshua A. Danish, Indiana University \\ Deborah A. Fields, University of Pennsylvania
}

To be published in the Canadian Journal of Mathematics

\begin{abstract}
One approach to promoting successful engagement of underrepresented groups in mathematics classrooms is Culturally Relevant Pedagogy (CRP). However, it has been argued that CRP risks essentializing students or watering down academic content. We report our analysis of a case study of a group of three $6^{\text {th }}$ grade students who took part in a 6-week mathematics curriculum. This curriculum used Geographical Information System (GIS) maps to engage students in designing personally meaningful research projects while learning about measures of central tendency (i.e., learning statistics). The case study was chosen as representative of how students in this urban classroom (47 total) successfully navigated the curriculum. While successful, the intervention highlights the kinds of negotiations that students engaged in with each other, the teacher, and the curriculum as they co-constructed their own meaning of relevance. The goal of our analysis is to illustrate the importance of recognizing multiple forms of relevance and supporting ongoing negotiations of these multiple forms.
\end{abstract}


Fostering the engagement of a diverse group of students in statistics education (or more generally mathematics education) while simultaneously facilitating their conceptual development can be a tricky balancing act. One proposal to foster engagement is organizing instruction around longer-term inquiry projects where the students choose topics that interest them personally (LaJoie, 1999). Another approach, culturally relevant pedagogy (CRP), attempts to capitalize on the cultural practices and identities of students by specifically building upon issues, topics and skills that are relevant to students and their lives outside of school (Ladson-Billings, 1995). Both of these approaches can run into trouble when it comes to negotiating the balance between what engages students and what supports the learning of mathematics. On the one hand, one of the most difficult aspects of statistics is developing a question that can be answered with data (Konold \& Higgins, 2002). As a result very few teachers, curricula, or research projects give the students a free hand in choosing their own topic. On the other hand, trying to develop statistical understanding through pre-determined projects and topics, no matter how steeped in culturally relevant or community based issues, runs the risk of alienating or essentializing groups of students based on broad generalizations and cultural stereotypes (Enyedy \& Mukhopadhyay, 2007).

In this paper, we report on a culturally relevant statistics project that culminated with students choosing their own statistical questions to pursue. The project was organized around the premise that relevance derived from familiarity with the context, combined with relevance derived from the utility of the findings to address real life issues, would lead to inviting more students (i.e., not just the students who historically performed well in school) to participate successfully in mathematics. The unit, while successful, was not without its ups and downs. We were particularly surprised by the nature of the challenges that arose as the teams of students worked to select a topic, as well as the at times unexpected consequences of their choices. After exploring the ways that familiar contexts can provide resources for meaning-making and critically examining the tensions that arise from an interpretation of cultural relevance that rests primarily on familiarity, we propose that a more productive and scalable path for culturally relevant mathematics teaching is to focus on the processes through which relevance is made visible, in particular the negotiation of what are legitimate contexts and how those can be mathematized.

Our findings point to the importance of not pre-determining what topics will engage the students. It is the give-and-take process of negotiating what counts as relevant to the students in the context of what can be mathematized that is critical in this type of learning environment. We propose that three interpretations of relevance-relevance of local knowledge of the context, relevance from an authentic purpose, and the relevance of in and out of school social identities (Enyedy \& Mukhopadhyay, 2007) - contributed in different ways and at different times to the negotiation between the students and the teachers of an adequate topic for the final project.

Our analyses revealed an ongoing process of negotiation: between aspects of what individual students found relevant in their own personal lives and what they found relevant in the classroom context; between students' interests and the classroom version of mathematics (i.e, using Geographical Information System maps, etc.); and between each of these and a normative sense of mathematics as contributed to the discourse by the teacher and researchers. This negotiation occurred over time between students and their peers as well as the teaching staff, with both groups engaging in moves to reach collective agreement on a meaningful project to pursue for the duration of the class. In these negotiations, all of the different forms of relevance are evident and support the negotiation in different ways. We will illustrate this process by describing the sequence of events through which one group of students moved through the process of selecting and refining an answerable research question, analyzed the data, and refined their findings into a final presentation. We will focus our analysis upon the ways that different forms of relevance appear to engage students into the larger conversation, and how these relate to conventional mathematical practices. Our goal through this analysis is to present a refined vision of culturally relevant mathematics, one that highlights it as an ongoing process of negotiation between different visions of what is relevant. 


\section{Theoretical Framework}

Researchers who have spent their careers designing learning environments for particular racial identities, cultural heritages, and/or languages argue that to foster success we must look beyond constructivist teaching methods. In order to judge for whom a learning environment will be effective, we must also examine it in relation to the learner's existing cultural repertoires (Lee, 2003; Martin, 2004). Although there are many different approaches to culturally relevant pedagogy, all the approaches share the goal of challenging the mono-cultural pedagogy employed by most schools today. Specifically, they aim to redirect our attention to the strengths and resources available to different groups of students so that curricula can be designed in a way that empowers all students to be successful in learning and using mathematics.

It may be helpful to note that there are at least three ways that one can interpret the term "relevant" in culturally relevant pedagogy by locating the relevance in 1) the content or topical context of the lesson; 2) the perceived value to students' lives outside of school; or 3) the processes and participation structures through which the students engage with the lesson (Enyedy \& Mukhopadhyay, 2007). In our analysis we are not merely arguing that relevance can generate interest or spark motivation. Instead, we are pursuing how different forms of relevance permeate and mediate students' sustained engagement, which extends beyond the initial reaction and colors student interaction throughout the activity. We explore each of these forms of relevance and how they affect student interactions and meaning making below.

\section{Relevance of Content/Context}

The first interpretation of cultural relevance-as academic topics couched in familiar contexts that build upon students' existing competencies and prior knowledge for academic success - is certainly the most intuitive and most widespread approach. This is a straightforward interpretation of relevance that extends the traditional constructivist focus on the prior knowledge that students bring to an instructional context. Here prior knowledge is not limited to physical abstraction (knowledge from the observation of objects and events) or logico-mathematical abstraction (knowledge from reflection on ones own actions including reflection on one's own mental actions) but is extended to include social and culturally sensitive knowledge (Lee, 2003). There are numerous examples of this type of work (e.g., Lee, 2003; Moses \& Cobb, 2001; Rosebery, Warren \& Conant, 1992). For example, the Algebra Project (Moses \& Cobb, 2001) uses students' familiarity with the transit system and other everyday contexts to help students connect their cultural knowledge to mathematical concepts such as positive and negative integers. In this interpretation familiar contexts are both a resource for sense-making and a resource for engagement. An advantage of this approach is that using familiar contexts legitimizes the larger pool of skills and knowledge that the students are familiar with through their family and social networks as resources to understand the academic content.

However, it is not always clear that there is a clean mapping between the students' funds of knowledge (Moll, Amanti, Neff, \& Gonzalez, 1992)-the knowledge that the students bring to school about the contexts and practices that are familiar in their home culture-and the mathematical content to be learned. Additionally, to the extent that we can find familiar contexts that map onto the academic content, we still run the risk of transforming the contexts in unproductive ways when we bring out-of school contexts into school. Walkerdine (1988) provides an example of how shopping was used to teach arithmetic. In translating shopping into school activities some of the fundamental aspects of the source context were transformed such that students who understood the shopping context well were actually at a disadvantage unless they could see that the real game was to ignore the context (and what you know about this situation) and instead only use the school procedures. This is quite the opposite of CRP's intent when bringing a familiar context into a school activity.

\section{Relevance of Authentic Purpose}

The second interpretation of relevance focuses on framing academic content as valuable to one's life outside of school as a way to critique social injustice (e.g., Gutstein, 1997; 2003; 
Morrell, 2004). This interpretation aims to balance the development of students' academic competence with developing their critical consciousness. From a traditional mathematics educator's point of view, mathematics becomes a key analytic tool to understand and critique social justice issues. As such, it might be characterized as using real world contexts that are related to issues that adversely affect the students or their community to promote motivation and engagement. However, current theories of learning suggest that students' understanding of a tool or concept is dependent upon their understanding of its utility (e.g., why was it developed in the first place and what problems does it help to solve) (diSessa, 2004; Enyedy, 2005). When students don't understand the purpose for such concepts, they are less likely to use them effectively. This would suggest that linking mathematical ideas and procedures to contexts that students value does more than just motivate students, and also does more than just develop students' critical consciousness. An authentic purpose linked to a mathematical idea may affect both the depth of understanding as well as the range of contexts in which students will apply a mathematical lens.

An excellent example of this interpretation of cultural relevance is Gutstein's (2003) work with middle school Latino/a students where he taught mathematics as a tool to evaluate and critique social justice issues-both local and global. Gutstein (2003) has shown that minority middle school students who participate in mathematical investigations around issues such as farm workers' wages, the distribution of global wealth, and urban planning become more engaged, develop a sense of socio-political consciousness, learn to think mathematically, and develop mathematical identities. As a result, Gutstein's (ibid.) students passed their mathematics classes, graduated from the eighth grade, and made significant gains on standardized tests. Thus, this version of culturally relevant pedagogy simultaneously pursues a pedagogy of access to create more opportunities for students within the current educational system, and a pedagogy of dissent to fundamentally change the nature of that same system (Morrell, 2004).

While in the small number of existing studies this approach has been effective, it too is not without potential drawbacks. One limitation is the difficulty in effectively balancing the academic goals and practices with those needed to motivate and facilitate social critique. For example, in piloting a unit for high school students to learn statistics by investigating de facto segregation and educational inequities in the Los Angeles area, we found that tensions emerged between creating the conditions that organized the students into cohesive groups of social justice advocates, and creating the routines and norms that fostered a critical examination of evidence that was necessary for the students to learn statistics (Enyedy\& Mukhopadhyay, 2007). Students approached the investigation assuming-based on their local knowledge of their own school and community - that they already knew inequities existed. Honoring this local knowledge was an important part of our approach to culturally relevant pedagogy. However, honoring their local knowledge led the teachers to miss opportunities where they could have encouraged students to critically examine their own and their peers' confirming evidence. Without this encouragement, advocacy for a position dominated and students did not develop a critical stance towards data. As a result, the depth at which they learned the statistical concepts was limited (Enyedy \& Mukhopadhyay, ibid.). The example demonstrates the difficulty that teachers will likely have in navigating multiple goals and values when they attempt to implement curricula grounded in this approach to CRP.

\section{Relevance of Practices}

The third interpretation of cultural relevance is to focus on the process rather than the content of instruction. The premise here is that as learners move across the settings of everyday life, they participate in many different forms of culturally organized activity. In doing so, they develop repertoires of practice (Gutiérrez \& Rogoff, 2003) that are well adapted to different parts of their own lives. Repertoires of practice describe students' patterned ways of acting which include the kinds of language, organization, and timing of practices such as asking and answering questions, disagreeing with peers, and marking topics as interesting, important, or irrelevant. The practices that students encounter in school may be more or less familiar to them (i.e., they may 
overlap, conflict, or complement what they do elsewhere) depending on their histories of participation across the various settings of their home and community. Instructional interactions are more likely to be effective when students' existing repertoires of practice match or parallel the practices that are expected of them in school. Similarity of practices help students to successfully negotiate ways of being relevant within the multiple communities that they move between, including their home, friend groups, and institutions such as the classroom.

Even within a given context, students may be asked to negotiate among multiple repertoires of practice. For example, in the classroom, students may find themselves negotiating between the practices that are most relevant to their peers, and those that are expected by the teachers. This negotiation between multiple repertoires of practice may be challenging for some students, as Brown (2004) noted when he examined students' adoption of scientific discourse practices in the classroom; students sometimes felt they had to give up being relevant to their peers in order to be relevant academically. Adopting new ways of talking to communicate about science in the classroom could alienate their peers, leading to difficult choices about which community practices one chooses to ratify as relevant. Our contention is that faced with such tensions, not only will students find it difficult to balance these competing demands, many may choose to privilege their peer group practices over the classroom academic practices, a choice that may have serious implications for their academic success.

One possible solution to this tension between the repertoires of practice that students value within their peer groups and those that are valued by teachers is to create classrooms that include a hybrid set of practices. In fact, Barton, Tan, and Rivet (2008) argue that students actively try to bring ways of acting from other settings of their everyday lives into classroom contexts. When these efforts are accepted in the classroom, students blend practices from other settings with the local practices in school settings, and develop "hybrid" practices. These new hybrid ways of acting may in turn change the acceptable ways of being in the classroom. Barton et al. illustrated the benefits of developing hybrid practices when they described a situation in which a student made use of a popular song to create a mnemonic for remembering science content. The teacher then legitimized this practice, effectively honoring the students' attempt to achieve social recognition both from peers (with an interest in popular music) and from the science classroom (largely recognized through the teacher's positive comments). Gutierrez, Rhymes \& Larson (1995) referred to this kind of environment as a "third space" to capture the local negotiation between students and classroom authorities about what counts as legitimate participation, resulting in the development of hybrid practices meaningful to both parties.

\section{Negotiating relevance in the classroom}

In our study we examine the ways in which students' existing repertoires of practice were brought into the process of selecting a research question during a curriculum unit. The students did so primarily in groups of three, and many of the local negotiations were within these groups. However there were also other local negotiations at work - between the students in a small group and the various adults (the teacher and a handful of researchers) who worked with them at different points and between the small group and the larger peer group of the whole class. Thus, the students had to negotiate with their peers and with the adults in the classroom to determine which content, purposes and practices were viewed as relevant.

As noted above, regardless of which meaning of relevance we examine, tensions may arise between the concepts, purposes, and practices that the various stakeholders see as relevant. In particular, tensions may arise between the teacher as a proxy for "school" requirements and the students. One of our goals in designing culturally relevant mathematics curriculum is then to create "third spaces" (Gutiérrez et al, 1995) where the students' and teacher's views of what counts as relevant merge through negotiation. We appropriate Gutiérrez et al's term "space" here to make explicit the ways that stakeholders may position specific content, purposes, or practices as legitimate and/or desirable in the current context; this positioning effectively divides the students into those who are legitimized and those who are not. Gutiérrez and her colleagues described a situation in which a teacher had an opportunity to 
create such a space, and yet did not. Our analyses of the classroom interactions further reveal that these spaces are in fact negotiated and re-negotiated in a number of different ways which we will describe below. Furthermore, we argue that it is important to unpack each space even further as the practices and positioning that define them are not always consistent. For instance, the "official" space of our classroom was rather complicated. It included the goal promoted by the researchers (e.g. math can be useful for community activism) which at times ran counter to the more traditional goals and practices of schooling that the teacher had enacted up to this unit. Likewise, the unofficial space that the students inhabit is not monolithic-each student contributes in a unique manner, and at times these contributions may come in conflict with each other. We argue that these points of conflict may be productive as the participants negotiate a shared space that encompasses content, purposes, and practices that are meaningful to all of the participants.

\section{Study Design \& Methods}

The Community Mapping Project (CMP) was carried out in a Los Angeles middle school with an ethnically diverse student body (46\% Hispanic, 35\% Caucasian, 12\% African American, and $5 \%$ Asian and/or Pacific Islander). $41 \%$ of the school's students received free or reduced price lunches. Two sixth grade classrooms with a total of 47 students engaged with the CMP unit three days a week (approximately1 hour) for six weeks.

The CMP consisted of two main parts, both of which were conducted primarily in small group work. For the first three weeks students were given two structured activities meant to familiarize them with the two kinds of computer software used and to introduce them to thinking about statistics about social inequities in Los Angeles County. The two kinds of software were MyWorld (Edelson et al., 1999), a GIS mapping tool where data were layered onto a map of Los Angeles County, and TinkerPlots (Konold, 2005), a graphing tool particularly useful for exploring issues of central tendency in statistics (mean, median, mode). During the second three weeks student groups created their own research questions to pursue, analyzed data relevant to their questions, and prepared, gave, and evaluated each other's final presentations.

We collected two primary kinds of data: pre/post-tests and videos. Students were given a pre/post-test on the statistical concepts addressed in the unit adapted from Konold and Higgins (2002). Analyses of the tests show the project was moderately successful at achieving its instructional objectives. Descriptive statistics were obtained on performance on the pre-test and post-test items. For the 47 students, the average pre-test score was $3.39(S D=2.01)$ out of a possible of 13 points. The average post-test score was $5.79(\mathrm{SD}=3.03)$. A paired-samples t-test was conducted to compare pre-test scores and post-test scores. While the means were low, the post-test scores were significantly higher than the pre-test scores, $t(46)=t=-5.249 ; p<.005$.

We also videotaped the whole class sessions in addition to four case-study groups of three students each, two groups from each class. Additionally, all artifacts from the project from all groups was collected including worksheets, scratch paper on which they brainstormed research questions, and Powerpoint slides used in their final presentations.

To analyze the video data itself, we used an iterative approach similar to what Erickson (2006) describes; going through cycles of examining the corpus of video data, preparing initial hypotheses, and then reviewing the data while adjusting the hypotheses as needed. Specifically, we first examined the entire corpus of case-study data, creating activity logs of the videos with time-indexes to the major events in order get a rich sense of the overall process through which the different groups conducted their work. We then chose one group to pursue for a more indepth analysis because it directly challenged our preconceptions. As we reviewed the data for the case-study group, creating and refining conjectures about the process through which the students negotiated a meaningful topic for their research, we also compared these conjectures to the other case-study groups to verify that we were not basing our analysis upon an outlier that was not representative of the class. In cases where our findings were unique to the case-study group, we focused our analysis elsewhere in an attempt to construct a narrative that documented more general patterns within our dataset. 
In our specific analyses, we were also guided by grounded approaches (c.f., Charmaz, 2000), in setting aside or 'bracketing' our pre-existing assumptions as the designers of the lessons. One of the largest preconceptions that had to be bracketed and put aside was our expectation that students would take up the relevance of the topics as we had designed them. It was clear from the topic the students eventually selected (a correlation between the number of females in a neighborhood and the number of rapes) that we either had to dismiss this group's choice as our failure to keep the students on-task, or we had to attempt to recover the participants' perspectives and assume instead that there was a rationale and legitimate reason for what seemed to us an odd choice. It was our choice to try to recover the students' perspectives on this form of mathematics instruction that led us to focus on negotiation rather than on the direct contribution of relevance as a resource for statistical understanding. We identified the two days of negotiation concerning the groups' research questions as pivotal in their negotiations of relevance and transcribed videotapes for these two days. From these transcripts we traced how the topic arose, ran into dead-ends, and shifted over the two days. Next, for each shift we created conjectures regarding why the topic changed. Changes to the topic were often tied to who was advocating for a change or revision of the topic in the moment. Finally, we reinserted our preconceived notions about three types of relevance to see how much light they shed on this process by highlighting the role that relevant content, purposes, and practices played in guiding the students as they negotiated a topic for their research project.

\section{Findings}

Our analyses reveal an ongoing process of negotiation: between aspects of what individual students find relevant in their own personal lives and what they find relevant in the classroom context; between students' interests and the classroom version of mathematics (i.e, using GIS maps, etc.); and between each of these and a normative sense of mathematics as viewed by the teacher and researchers. This negotiation occurs over time between students and their peers, as well as the teaching staff, with both groups engaging in moves to reach collective agreement on a meaningful project to pursue for the duration of the class. In these negotiations, all of the different forms of relevance are evident, and support the negotiation in different ways. We will illustrate the process through which students negotiated between the content, purposes and practices that they each viewed as relevant by describing the sequence of events through which one of the case-study groups selected and refined an answerable research question, analyzed the data, and refined their findings into a final presentation. We focus our analysis upon the different kinds of negotiations that occurred within the group, both in the presence of the teacher, and when the students were working independently. Our goal through this analysis is to illustrate how culturally relevant mathematics was an ongoing process of negotiation between the content, purposes, and practices that are seen as relevant by the participants. We believe that this analytic approach represents a synthesis of prior approaches, and demonstrates the utility of examining the process through which students in a classroom define their own local vision of relevance in practice.

\section{Mark, Jasmine and Lorena: A Case Study}

To begin describing our findings we discuss one small group of three students: Mark (African-American), Jasmine (Latina), and Lorena (Latina) ${ }^{1}$. We begin our analysis two weeks into the curriculum after the students have already completed two earlier activities meant to familiarize them with the software tools. For this activity the group had two days to brainstorm and refine a research question including specifying the data they would use to answer that question. While they began with a question about "why are there so many whites in Santa Monica" (one of their local communities that is a relatively wealthy suburb of Los Angeles), over the course of the two days they transitioned to the dramatically different question of whether there are more "rapes where there are more females." While at first this transition between questions

${ }^{1}$ Pseudonyms are used for all names 
surprised us, analysis of the video shows the students' struggling to find a question that was answerable with data, relevant to their lives and that positioned their social identities in a privileged position.

It is important to note that, as the topic migrated and evolved, both the unit's focus on community relevance and personal relevance all but disappeared, even though both were central to the unit as conceived and important to the history of how students chose their topic. Below we discuss in detail some of the important transitions in the group's thinking about their research question and the tensions they navigated that contributed to the shaping of the question.

\section{Problems, questions, and data}

Soon after Lorena suggested the question "why is there so many white people as opposed to other race?" one of the researchers, Enyedy (identified as $\mathrm{N}$ in the transcripts), approached the group to work with them. After hearing their ideas for questions, he raised the problem of the fit between the "why" questions that had been proposed and whether they could be answered using data. In this specific case students only had data about the number of each ethnicity in a census tract, but no direct survey data about why people chose to live where they lived. More generally, students have great difficulty in forming statistical questions that are specific enough and constrain people's interpretation such that the question generates the right type of data (Konold \& Higgins, 2002; Roseberry et al., 1992). Lorena's question could be answered using so many different types of data (e.g., income data/housing prices, survey data of people's preferences, access to public transportation, crime data, etc.) that it would need to be dramatically narrowed before it might be answered with the census data. The students' interaction did not immediately lead to a resolution of this tension between questions that have real world relevance and ones that are answerable with data. The exchange ended, however, with a plan to continue brainstorming different topics.

Excerpt 1

Even before the researcher problematized the question the students had suggested, one of the students began to question whether their question was truly a "problem" (line 2). Mark was challenging the social relevance of an ethnically unbalanced neighborhood rather than a problem in the mathematical sense. This is evidence that Mark was already trying to balance multiple tensions in choosing a research question - a topic of personal interest and a question that addressed a social problem. He doubted that the question adequately fulfilled his second criterion. The researcher added a third consideration into the mix; how well the question fit with the data. Here we see a tension between the funds of knowledge (i.e., personal interests) of the students, school norms and practices (i.e., answering the question that the teacher intends), curricular goals of social justice (i.e., is this really a "problem" for the community?), and norms for good statistics questions (i.e., a specific question that can be answered with data).

\section{Students push their interests}

Later that class period, when it was the group's turn to report their question, Mark publicly raised their ongoing concerns about how well it met the different emergent criteria for a good question saying, "Why are there so many whites in Santa Monica... I didn't make up the question and it's not really a question..." This is an important move because it demonstrates how Mark was beginning to distance himself from the question, essentially demonstrating that it was not entirely "relevant" to him, as he had previously said.

When the students returned to their deliberations, they began to generate new questions. Each time they generated a new question, Mark immediately asked if they could prove it with data (lines $3 \& 8$ ), privileging the classroom norm that was previously promoted by the researcher. Lorena then also took up this practice as she asked the teacher how they could "prove our question on the computer?" 


\section{Excerpt 2}

Here we see that the students were still struggling with and quite aware of the multiple constraints in choosing a question. They were still trying to choose an authentic problem, one that can be phrased as a question, and in turn can be answered with data. When the teacher was drawn in to the discussion, he suggested using crime statistics and API scores (a relative measure of school quality) as measures for why white people might choose to live in Santa Monica. More importantly, the teacher created a narrative structure that linked the question to the data. Expanding on this narrative of why people might want to live in one place over another, Mark further suggested distance to the beach as data relevant to their question. Implicit in all three of these kinds of data was the assumption that white people had choices of where to live, as opposed to other ethnic groups, and that Santa Monica was a privileged location to live (less crime, higher achieving schools, and a short distance to the beach).

After this conversation the group began to voice and finally articulate a discomfort with the question because of the way it gave prominence to white people. The first researcher $(\mathrm{N})$ returned to the group to check on their progress. Mark said they had a question but didn't want to do it. The researcher suggested trying to modify it to make it more interesting, and this helped Mark articulate why he doesn't like the question saying, "I don't want to make it about why do white people blah blah blah". In essence, the researcher enabled Mark in this moment to return to what he found personally relevant, building off of the current candidate question. This is a move that we see often in our data, particularly with students like Mark who, based on our observations and teacher reports, are used to playing the "school game" and following the worksheet, often at the expense of their own personal interests. In this case, we see how the researchers and teacher played an active role in helping to bring the students' ideas and interests into the fore.

\section{Excerpt 3}

When we look at the students' worksheet, it is even more clear that while the question satisfies the mathematical aspects of a good question it does not fully satisfy the students' desire for a problem that is relevant to them. The students were asked to fill in a chart that outlined what they know, what they want to know and the numbers or data that could help them answer the questions. For the question "Why there are so many whites in Santa Monica," the students listed crime data, distance from the beach and API data for the schools, but conspicuously left blank the columns for what they know and what they want to know about the topic. In light of this, it is not surprising that on the second day they started from scratch and began to brainstorm new topics that would fulfill all the requirements that they had implicitly been trying to balance.

\section{Day 2 Bringing the negotiation to a close}

On the second day, the group left the question about white people behind and explored questions about parks and violence around Los Angeles County. They took turns clicking on different areas of the GIS map based on their ideas about which areas had more violence. They continued to try and balance a personally relevant context (i.e., meaningful and interesting), relevance to the community (i.e., purpose) and mathematical relevance as they continually negotiated the third space with each other and the instructors. They also introduced a new aspect, bringing their peers in the class into their negotiations. Specifically, they introduce a desire to have a unique question that no other group was addressing, and one that had some amount of shock value.

At the very beginning of the session they focused on personal relevance. Unlike the first day, they started framing the questions, not about whites, but about things that mattered to or defined them and their families. 


\section{Excerpt 4}

There were several markers of personal relevance, phrases such as "my people" "I am a little gang banger" "my cousin" and "your/my brother". The links to violence and the ways that violence limits one's access to places such as parks links the topics to real problems facing the community. However, the focus on personal and community relevance has, at least for the moment, eclipsed the mathematical criteria for an adequate question. Although all of this conversation, and the ones that follow, occur while the students explore the GIS data on various types of crimes in Los Angeles, none of these topics are phrased as questions, and none of them are directly linked to data. It may be, therefore, that the data continues to constrain students' work, but in a more fluid and natural way as the GIS maps naturally make apparent to the students the set of questions that might be answered with data rather than requiring the students to think about a question first, and the data second. In this way, relevance to the data is built into the activity and continues to play a role even though the students were not, at this point, asked to explicitly address the data they might use to answer their questions. For example, the first mention of rapes as a possible topic for exploration occurs when the students appear to be moving through the crime data on-screen, clicking on items in the dataset. The students have at this point refined their search of the data to be about crime, and are clicking through the dataset while their attention is focused on the computer screen. At this point Lorena turns excitedly to Mark and says "We can do number of rapes!" Mark's initial response after clicking is enthusiastic ("Oh yeah!") but quickly subdued when he points out that he doesn't see any. Lorena replies by pointing to the screen, presumably identifying an area of the map where rapes did occur in sufficient number to be visible with the current settings of the map. The topics of rapes is temporarily laid aside until excerpt 5 .

This kind of data-mining was quite common throughout the corpus of video data, as students explored the data by identifying the variables that appealed to them from the on-screen list, and then clicked to see instantly whether there was a pattern that caught their eye, often moving to either change the variable (if it was not interesting) or narrowing their exploration to a geographical region of interest to them if there was a clear pattern in the data. While this form of data-mining is not commonly desirable in a classroom setting, we argue that it was quite effective in this case, affording the students an opportunity to "play" with the data as they attempted to find a set of variables that satisfied the multiple forms of relevance that they were attending to. Once the topic was chosen in this manner, students could then adopt more mathematically normative approaches to working with the identified variables.

As the three students continued to brainstorm their question, they eventually returned to mentioning school as a factor influencing their decision. They explicitly discussed school, not mathematics. In particular, it was the social dimension of school and their current classroom that they introduced as relevant, not the mathematical norms. Specifically, they addressed the value that they saw in having a unique topic to present, and in having a topic that was exotic, taboo, or contained some aspect of shock value. Once the students selected a specific topic that appeared to interest them (rapes), they immediately brought their local knowledge and interest to bear as they continued to refine their search through the data via the GIS tool. In lines 6-9 the students had decided to examine the incidence of rapes in neighborhoods that they had discussed before as both interesting to them, and neighborhoods that they know to be quite violent.

\section{Excerpt 5}

In their final project the group compared three communities within Los Angeles County in terms of the number of females that live there and the number of rapes per capita that occurred in the year (Figure 1). Further, they used the distribution of the entire county to place the three communities above or below the county's mean and median (Figure 2). Finally, they produced a map of Los Angeles County (Figure 3) where color represented the number of rapes and the 
thickness of the border of the census track represented the number of females who lived in that area.

Figures 1-3 ABOUT HERE

\section{Discussion}

Projects in this curricular unit were successful to the degree that the teacher and/or researchers engaged the students in negotiations to develop a topic that was answerable with data, that was consistent with the norms of school, that engaged the students personally, and that fit with the data that was available. More importantly, these negotiations were themselves opportunities for the students to engage in a renegotiation of the very participation structures of the classroom, helping to shape the practices that would be viewed as legitimate within this classroom. These new, hybrid, classroom practices involved a greater degree of agency for the students who were allowed to choose what was relevant to them and how to resolve tensions between different forms of relevance ${ }^{2}$.

In negotiating relevance of their question within the local social setting of the classroom, the students first lobbied for recognition from each other. During the two days spent choosing a research question, the students shared jokes, knowledge of each other's families, information about what could be robbed, and local school gossip. While these practices might be easily overlooked as simply the process through which middle school students make friends and interact with their peers, we argue that these familiar practices were instrumental in inviting the students into mathematical discussions. For instance, when Jasmine said, "I'm a little gangbanger" we believe that she was doing more than simply suggesting that her group study "gangs" as part of the research question; her statement about being a gangbanger could be seen as both another bid for that topic and as a way to pose her own experiences as relevant to the question they were developing. She succeeded in getting recognition from her group members they gave her attention as they questioned whether she was actually a gangbanger or whether it was just her brother, and Mark reacted in whispered shock, "Your brother's a gangbanger?" The conversation then moved to sharing who had family members who were in gangs before moving back to the developing research question about violence in local areas. There were many short conversations like this in the larger two-day dialogue, illustrating the ways that the group negotiated a question that would be relevant to their shared experiences.

Second, the students engaged in the practice of garnering positive attention from their classmates. They thought their question was a good topic in part because it was unique from the other projects and had a certain shock value that would bring peer recognition. This points to a desire to be unique from the other groups' projects and also to be seen as unconventional against the backdrop of traditional schooling. Though we as researchers had thought of the final presentation as something that would provide a legitimate academic audience, we neglected to consider the students' desire to be relevant to the norms and values of their peers - a set of relationships that existed not only within the mathematics classroom but stretched out more broadly as the students attended classes and visited each other during breaks and lunches.

Third, this group's final research question was also connected to the statistical concepts they were required to learn and helped them construct their understanding of the concepts of distribution, mean, median and mode. The students learned through interactions with the

\footnotetext{
2 This may have contributed to making the classroom more inviting for students who had not yet found a space for themselves in a traditionally organized classroom with the teacher at the center and where tasks, problems and solutions were prescribed. Although beyond the scope of the current paper, the teacher told us that students who typically did not actively participate in the classroom began to do so and that they enjoyed the unit. However, some students - typically those who had excelled under the traditional organization-were less enthusiastic, at times complaining and asking when the classroom would go back to doing "real" math.
} 
researchers, teacher, and class artifacts (e.g. the worksheet, the GIS software) what would count as a legitimate form of participation in the academic aspects of class. Thus they worked to meet the local, socio-mathematical norms of the classroom as represented by the teacher, researchers, and unit artifacts. Through these local negotiations for relevance, the classroom became a third space with emergent patterns of participation, supporting the students in engaging in hybrid practices that were at the same time familiar to them, and also satisfied the classroom goals of "doing math".

We believe there is much more that needs to be learned about how to manage this process of negotiating multiple practices and norms. The statistical concepts, although learned in and applied meaningfully to a context, were not developed with as much depth as we had hoped (as evidenced by the very modest learning gains). Likewise, the authentic purpose and critical consciousness we hoped to foster with a social justice mathematics unit was transformed during the negotiation process in unanticipated ways and more importantly in ways that did not necessarily fit with the research team's preconceived notion of what a legitimate social justice topic would look like. Both of these outcomes should be noted as an area of concern for any educator interested in taking on such a unit with their students. Both the successes and the failures of this intervention point to the importance of negotiating practices and norms in this form of culturally relevant pedagogy. Such negotiations cannot be dictated by the teacher, nor can the students be given complete control. Both parties must legitimately be engaged in the negotiation process in order to avoid creating artificial activities under the guise of authenticity; engaging both parties in co-construction of the local meaning of relevance helps to ensure that the end product is, in fact, relevant and meaningful to all of the participants.

In this case, throughout the two-day long search for a research question, three different forms of relevance-familiarity of context, authentic purpose, and repertoires of practice-all had to be negotiated. Familiarity of context came up frequently as students used their cultural and local knowledge to explore the data and suggest questions. First, the students drew on their own knowledge of a racial divide - that there are more whites in Santa Monica as opposed to other areas of Los Angeles - to suggest a 'why' question for why this could be. Perhaps because they already thought that there was a divide, the why question was more relevant than asking whether there were more whites in Santa Monica. Second, the students used local knowledge about which areas of the county might have more violence to explore the GIS map, trying to figure out where various cities they knew of were on the map and whether there was indeed more violence there.

Authentic purpose also played a role in the questions they generated even though it diminished as they transitioned from their initial question of race to their final question about rapes and females. The group's initial question regarded a racial and economic divide in the local community that privileged white people. Once they decided not to pursue that question, they considered a range of questions that had personal implications for their lives. Mark suggested "what races go to parks" would be good because "you know some of my people don't want to go to the hood park because they're gonna get shot up." Concern about violence was of daily relevance because of where parents would allow them to go and because of family members involved with gangs.

Finally, the students refined their research questions by negotiating relevance to local social practices and norms. Within their negotiations over the research question, the students worked to obtain social recognition from each other, from their classmates, and from the instructors. These negotiations manifested themselves in the moment-to-moment interactions between the students, their peers and the adults as they tested the boundaries of what practices were legitimate in this new hybrid educational context they were co-constructing. Their final research question about rapes and females was an unexpected development for the researchers. However, it was a success from the point of view of creating a third space where negotiating relevance involved a (sometimes awkward) process of negotiation among different groups, practices, and norms in the classroom.

Our analysis contributes a refined interpretation of culturally relevant pedagogy. Instead of focusing on topics that embody various aspects of relevance, we argue that instruction needs 
to focus on engaging the students in a process of negotiating relevance-and in this process utilize their local knowledge, develop their own sense of local purpose, and draw on specific, preexisting practices of their culture, peer group, and community.

\section{References}

Barton, A., Tan, E., \& Rivet, A. (2008). Creating hybrid spaces for engaging school science: How urban girls position themselves with authority by merging their social worlds with the world of school science. AERJ, 45, 68-103.

Brown, B. (2004). Discursive Identity: Assimilation into the culture of science and its implications for minority students. Journal of Research in Science Teaching. 41(8). pp. 810-834.

Charmaz, K. (2000). Grounded theory: Objectivist and constructivist methods. In N. K. Denzin \& Y. S. Lincoln (Eds.), Handbook of Qualitative Research (pp. 509-535). Thousand Oaks, CA: Sage Publications.

diSessa, A. A. (2004). Meta-representation: Native competence and targets for instruction. Cognition and Instruction, 22, 293-331.

Edelson, D. C., Brown, M., Gordin, D. N., \& Griffin, D. A. (1999). Making visualization accessible to students. GSA Today, 9, 8-10.

Enyedy, N. (2005). Inventing Mapping: Creating cultural forms to solve collective problems. Cognition and Instruction 23(4), 427 - 466.

Enyedy, N. and Mukhopadhyay, S., (2007). They don't show anything I didn't know: Emergent tensions between culturally relevant pedagogy and mathematics pedagogy. The Journal of the Learning Sciences 16(2), 139-174.

Erickson, F. (2006). Definition and analysis of data from videotape: Some research procedures and their rationales. In J. Green, Camilli, G., \& Elmore, P. (Ed.), Handbook of complementary methods in educational research. (3rd ed.) American Educational Research Association.

Gutiérrez, K. D., \& Rogoff, B. (2003). Cultural ways of learning: Individual traits or repertoires of practice. Educational Researcher, 32(5), 19-25.

Gutiérrez, K. D., Rymes, B., \& Larson, J. (1995). Script, Counterscript, and Underlife in the Classroom: James Brown versus Brown v. Board of Education. Harvard Educational Review, 65(3), 445-471.

Gutstein, E. (2003). Teaching and learning mathematics for social justice in an urban, Latino school. Journal for Research in Mathematics Education, 34(1), 37-73.

Gutstein, E., Lipman, P., Hernandez, P., \& de los Reyes, R. (1997). Culturally relevant mathematics teaching in a Mexican American context. Journal for Research in Mathematics Education, 28(6), 709-737.

Konold, C. (2005). Exploring Data with TinkerPlots. Key Curriculum Press.

Konold, C., and Higgins, T. (2002). Working With Data: Highlights of related research. In D. Schifter, V. Bastable and S. Russel, J (Eds.), Developing Mathematical Ideas: Collecting, Representing, Analysing. Parsipany, NJ: Dale Seymour Publications.

Ladson-Billings, G. (1995). The dreamkeepers: Successful teachers of African American children. San Francisco: Jossey-Bass Publishers.

Lajoie, S. P. (1999). Understanding of statistics. In E. Fennema \& T. A. Romberg (Eds.), Mathematics classrooms that promote understanding (pp. 109-132). Mahwah, NJ: Erlbaum. Ladson-Billings, G. (1995). The dreamkeepers: Successful teachers of African American children. San Francisco: Jossey-Bass Publishers.

Lee, C. D. (2003). Toward A Framework for Culturally Responsive Design in Multimedia Computer Environments: Cultural Modeling as A Case. Mind, Culture, and Activity, 10(1), 42-61.

Martin, D. B. (2004). Optimizing minority achievement in rigorous mathematics courses: Challenging what we think we know. Maryland Institute for Minority Achievement and Urban Education First Annual Research Symposium, Maryland. 
Moll, L. C., Amanti, C., Neff, D., \& Gonzalez, N. (1992). Funds of knowledge for teaching: Using a qualitative approach to connect homes and classrooms. Theory Into Practice, 31(2), 132141.

Morrell, E. (2004). Becoming Critical Researchers: Literacy and Empowerment for Urban Youth. New York: Peter Lang.

Moses, R. P., \& Cobb, C. E. (2001). Radical equations: Civil Rights from Mississippi to the Algebra Project. Boston, MA: Beacon Press.

Rosebery, A., B. Warren and F. Conant (1992). Appropriating scientific discourse: Findings from language minority classrooms. The Journal of the Learning Sciences 2: 61-94. Rosebery, Moses \& Cobb, (2001).

Walkerdine, V. (1990). The mastery of reason: Cognitive development and the production of rationality. Routledge.

\section{Acknowledgements}

This project was funded by a post-doctoral fellowship from the National Academy of Education and the Spencer Foundation. We would also like to thank Matt Hart for his enthusiasm and insight in the design and teaching of this unit. Thanks also to Shuili Mukhopadhyay and Linda Kao for their help in the classroom and with the data collection. Finally, we wish to thank the three anonomous reviewers for their comments and critiques which made this a stronger article. 